UCRL-ID-123475

\title{
Lawrence Livermore National Laboratory Capabilities in Multiphase Dynamics
}

\author{
FECEIVED
}

Rose C. McCallen

MAY 051996

Sang-Wook Kang

OSTI

April 9, 1996

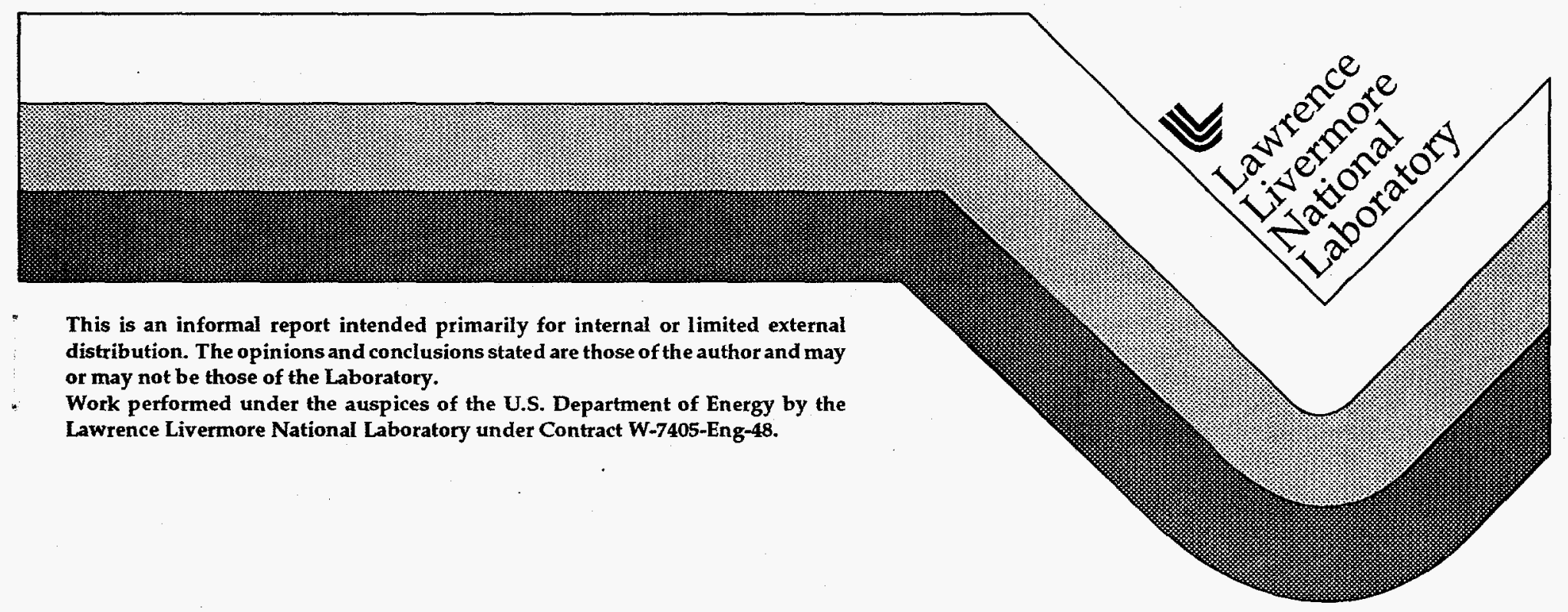

This is an informal report intended primarily for internal or limited external distribution. The opinions and conclusions stated are those of the author and may Work not be those of the Laboratory.

Work performed under the auspices of the U.S. Department of Energy by the awrence Livermore National Laboratory under Contract W-7405-Eng-48. 


\section{DISCLAIMER}

This document was prepared as an account of work sponsored by an agency of the United States Government. Neither the United States Government nor the University of California nor any of their employees, makes any warranty, express or implied, or assumes any legal liability or responsibility for the accuracy, completeness, or usefulness of any information, apparatus, product, or process disclosed, or represents that its use would not infringe privately owned rights. Reference herein to any specific commercial product, process, or service by trade name, trademark, manufacturer, or otherwise, does not necessarily constitute or imply its endorsement, recommendation, or favoring by the United States Government or the University of California. The views and opinions of authors expressed herein do not necessarily state or reflect those of the United States Government or the University of California, and shall not be used for advertising or product endorsement purposes.

This report has been reproduced directly from the best available copy.

Available to DOE and DOE contractors from the Office of Scientific and Technical Information

P.O. Box 62, Oak Ridge, TN 37831

Prices available from (615) 576-8401, FTS 626-8401

Available to the public from the

National Technical Information Service

U.S. Department of Commerce

5285 Port Royal Rd.

Springfield, VA 22161 


\section{LAWRENCE LIVERMORE NATIONAL LABORATORY CAPABILITIES IN MULTIPHASE DYNAMICS}

Submitted by:

Rose McCallen

(510) 423-0958

mccallen1@1lnl.gov

Sang-Wook Kang

(510) 422-7233

kang1@llnl.gov 


\section{CAPABILITY: NUMERICAL METHODS FOR MULTIPHASE FLOW}

Estimated Number of Professionals: between 10 and 50

Sponsors: DOE, OFA, DOD, private in-kind

Description:

ALE3D: Arbitrary Lagrangian Eulerian 3D Code

ALE3D is a general purpose code developed at LLNL that can model coupled fluid/structure interaction with heat transfer as well as chemical reactions. It is a finite element code which treats fluid and elastic-plastic response on an unstructured grid. ALE3D is currently being applied to a number of problems involving fluid/structural dynamics, including steady state and transient flows and shock hydrodynamics. For example, ALE3D is being used to model industrial problems such as casting, forging, and extrusion, in addition to the modeling of aeropropulsion systems. It is also being used to address fire safety of explosive systems.

ALEC: Arbitrary Lagrangian Eulerian C-code

A new generation ALE3D code is being developed for use on parallel machines. Like the serial version, it will have the ability to model fully coupled solid mechanics, heat transfer with phase change, and chemical reactions.

CALE: Arbitrary Lagrangian Eulerian 2D Code

CALE is a two-dimensional multiphase, multi-material, finite-element arbitrary Lagrangian/Eulerian general-purpose code for fluid-structure interaction phenomena. It can accommodate high-strain rate material properties during interaction. CALE has been applied to such diverse problems as a liquid jet impinging on a solid surface and the process of bubble formation/implosion in deep underwater situations.

Incompressible and Compressible Adaptive Mesh Refinement Codes

The compressible AMR code is based on a model of two-phase turbulent flow which can account for turbulent transport and entrainment of particulates. Adaptive mesh refinement (AMR) is used to follow the convective mixing process. The code can model an explosion and account for after burn effects caused by turbulent mixing of detonation product gases with air. The incompressible AMR code solves for 3D flow in the limit of zero Mach number and can account for bouyancy effects.

High-Performance Global Climate Modeling

We are developing an advanced generation of parallel climate models. These models can simulate long- and short-wave radiation, moisture convection, simplified ozone photochemistry, cumulus convection, precipitation, and riverflow.

Combustion Modeling

LLNL has established the unique capability to model chemical kinetic systems of combustion problems related to practical combustion systems such as internal combustion engines, industrial burners, and other practical combustion devices. 


\section{CAPABILITY: PHENOMENOLOGY AND CONSTITUTIVE THEORY AND MODELING}

Estimated Number of Professionals: over 20

Sponsors: DOE, DOD, private in-kind

Description:

CHEQ is a multiphase chemical equilibrium code that can model conditions that range from atmospheric pressures to chemical explosive pressures and temperatures from cryogenic to 10,000 degrees Kelvin. CHEETAH is similar to CHEQ in that it can treat multiple phases (solid and fluid) but only one fluid phase.

Constitutive models are being developed for modeling phase change of pure metals and alloys.

The turbulence modeling varies from the traditional Reynolds-average approach ( $k-\varepsilon$ to mixing-length models) to state-of-the-art direct numerical simulation and large-eddy simulation. This work is being done in both the compressible and incompressible regimes using both finite difference and finite element methods. 


\section{CAPABILTY: EXPERIMENTAL METHODS FOR MULTIPHASE FLOWS - ADVANCED DIAGNOSTICS, ADVANCED TEST BEDS, FACILITIES AND DATA BASES}

Estimated Number of Professionals: over 200

Sponsors: DOE, DOD, private in-kind

Description:

\section{Experimental Methods}

Hydrotesting: Hydrotesting is used to capture the dynamics of materials at ultrahigh speeds. Images are captured by our ultrafast electro-optic camera, to show the dynamics of an explosion. During such testing, our explosives produce pressures so high that solid materials, even when not melted, flow like fluids.

Flash X-Ray (FXR): FXR is used to produce high-resolution X-ray pictures of highdensity objects.

Piston: A gas-operated piston is used for impulse testing. The specimen can be thermally conditioned to match a desired environmental temperature.

High Pressure Strand Burner: The high pressure strand burner is used to determine the burn rate of energetic materials and will show evidence of multiphase burning.

\section{Facilities}

EMC: Energetic Materials Center

The Energetic Materials Center is a joint effort between Lawrence Livermore and Sandia National Laboratories. It has a staff of more than 200 scientists and engineers with proven expertise in high explosives, propellants, and pyrotechnics. Among its resources are several gun tubes, explosive firing tanks and bunkers, a shock tube, and a variety of the latest optical, electrical, and radiographic diagnostics.

Safety Test Facilities (Site 300)

The safety test facilities can be used to simulate arctic-to-desert conditions. For example, we can simulate accidents, ranging from handling drops to aircraft and car crashes to fuel fires. 


\section{CAPABILITY: MULTIPHASE FLOW APPLICATIONS}

Estimated Number of Professionals: over 50

Sponsors: DOE, DOD, private in-kind

Description:

The multiphase flow applications at LLNL range from defense applications to those of industrial interest. For example, there are several applications involving materials manufacturing, such as, the casting of metals and resin transport molding.

Other examples are related to environmental applications. For example, the modeling of particulate transport or pollutant dispersion for geophysical applications or the modeling of precipitation and pollution dispersion in atmospheric or climate modeling. 
